\title{
Optimizing Carbon Dioxide and Light Levels during in Vitro Culture of Theobroma cacao
}

\author{
Antonio Figueira and Jules Janick \\ Department of Horticulture, Purdue University, West Lafayette, IN 47907-1165 \\ Additional index words. cacao, ethylene, net photosynthesis, fructose, calcium, potassium, magnesium, phosphorus
}

\begin{abstract}
In vitro culture of axillary cotyledonary shoots of Theobroma cacao L. (cacao) under increasing $\mathrm{CO}_{2}$ concentration from ambient to $24,000 \mathrm{ppm}$ (culture tube levels) significantly increased total shoot elongation, number of leaves, leaf area per explant, and shoot dry and fresh weight. Although light was necessary for the $\mathrm{CO}_{2}$ response, the effect of various photon fluxes was not significant for the measured growth parameters. Net photosynthesis estimated on the basis of $\mathrm{CO}_{2}$ depletion in culture tubes increased 3.5 times from 463 to $2639 \mathrm{ppm} \mathrm{CO}_{2}$, and increased 1.5 times from 2639 to $14,849 \mathrm{ppm}$ $\mathrm{CO}_{2}$, but declined from 14,849 to $24,015 \mathrm{ppm} \mathrm{CO}$. Ethylene concentration in culture vessels increased under enriched $\mathrm{CO}_{2}$ conditions. Depletion of nutrients (fructose, $\mathrm{K}, \mathrm{Ca}, \mathrm{Mg}$, and $\mathrm{P}$ ) from the medium was increased under enriched $\mathrm{CO}_{2}$ conditions.
\end{abstract}

In conventional tissue culture, sugar is the carbon and energy source required for heterotrophic growth of the explant in vitro. Photosynthesis is partially limited by $\mathrm{CO}_{2}$ depletion in sealed culture vessels under ambient concentration during the light period (Desjardins et al., 1988; Figueira et al., 1991, 1991a; Kozai, 1991). Elevated light combined with $\mathrm{CO}_{2}$ enrichment has been proposed to stimulate photoautotrophism (Infante et al., 1989; Kozai, 1991). Explants cultured under autotrophic conditions have an improved survival rate during the acclimatization stage (Grout, 1988; Grout and Millan, 1985; Laforge et al., 1991; Lakso et al., 1986) and decreased contamination risks (Kozai, 1991). The $\mathrm{CO}_{2}$ levels employed in photoautotrophic systems in vitro normally range from 1000 to $4500 \mathrm{ppm} \mathrm{CO}_{2}$ (Desjardins et al., 1988; Infante et al., 1989; Kozai, 1991; Lakso et al., 1986).

The use of $\mathrm{CO}_{2}$ enrichment for in vitro systems generally has been associated with the promotion of photosynthesis. However, high $\mathrm{CO}_{2}$ concentration (chamber levels of $20,000 \mathrm{ppm}$ ) had a beneficial effect on shoot elongation and leaf development on detached axillary cotyledonary shoots and single-node cuttings from mature plants of Theobroma cacao L. (cacao), a species that had been considered recalcitrant under conventional protocols (Figueira et al., 1991). Woltering (1990) demonstrated that $\mathrm{CO}_{2}$ concentrations above $10,000 \mathrm{ppm}$ were beneficial to in vitro cultures of roses and gerbera, decreasing abscission, and senescence of leaves. These responses to such a high $\mathrm{CO}_{2}$ concentration suggest that another process besides photosynthesis may be involved.

The primary objective of this study was to optimize the $\mathrm{CO}_{2}$ concentration and light levels for in vitro growth and development of cacao axillary shoots and to investigate the physiological basis of the beneficial response to enriched $\mathrm{CO}_{2}$. In addition, we hoped that these studies would help elucidate the cause of the recalcitrance of cacao under conventional in vitro culture.

Received for publication 12 Mar. 1993. Accepted for publication 6 Dec. 1993. Journal paper no. 13,731 of the Purdue University Agricultural Experiment Station. We acknowledge the assistance of S. Shivashankar with the ethylene experiments. We thank CNPq/CEPLAC, Brazil, for financial support to Antonio Figueira. The cost of publishing this paper was defrayed in part by the payment of page charges. Under postal regulations, this paper therefore must be hereby marked advertisement solely to indicate this fact.

\section{Materials and Methods}

In vitro axillary shoot proliferation from cotyledonary nodes. Open-pollinated pods from UF613 and from progenies of the crosses SCA6 $\times$ Catongo, CC42 $\times$ Catongo, CC42 x P-7, UF613 $x$ SCA 6, Catongo $x$ UF 676, and UF $676 \times$ Catongo were obtained from the Intl. Cocoa Germplasm, Centro Agronomico de Investigacion y Enseñanza (CATIE), Turrialba, Costa Rica. Pods were washed, flame-sterilized, and opened in a laminar flow hood. The seeds were removed from the mucilaginous pulp and germinated on a Woody Plant Medium (WPM) (Lloyd and McCown, 1980) in baby food jars with $30 \mathrm{ml}$ of medium supplemented with $88.8 \mathrm{~mm}$ fructose and $7 \mathrm{~g} \cdot$ liter $^{-1}$ agar (Sigma). The medium was adjusted to $\mathrm{pH} 5.3$ before autoclaving. The culture room was maintained at $26 \mathrm{C}$ under $16 \mathrm{~h}$ photoperiods. Epicotyls were removed 4 to 6 weeks after seeds had germinated to induce axillary shoots from the cotyledonary node (Janick and Whipkey, 1985), and the cotyledonary nodes were recultured on fresh medium. Axillary cotyledonary shoots were collected 4 to 6 weeks after decapitation.

Carbon dioxide chambers. Elevated $\mathrm{CO}_{2}$ treatments were conducted in clear acrylic chambers located in a growth room. The chambers, not air tight, were continuously supplied with compressed $\mathrm{CO}_{2}$ and air-mixed with a flowmeter (Matheson, East Rutherford, N.J.). The $\mathrm{CO}_{2}$-air mixture was bubbled through distilled water and relative humidity inside the chambers ranged from $50 \%$ to $70 \%$, the same as in the growth room. The $\mathrm{CO}_{2}$ concentration in the chambers was measured using a gas chromatograph (model 8700; Carle GC, Broken Arrow, Okla.) with a thermal conductivity detector. Chambers were illuminated with VHO (SPELL) cool-white fluorescent lamps (General Electric, Pittsburgh). Chamber temperatures were higher than the growth room reaching $31 \mathrm{C}$ during the light period.

Optimization of light and $\mathrm{CO}_{2}$ conditions. In the first experiment axillary cotyledonary shoots $(\approx 5 \mathrm{~cm})$ were transferred to tubes $(44 \mathrm{ml})$ with $10 \mathrm{ml}$ WPM supplemented with $88.8 \mathrm{~mm}$ fructose, previously demonstrated to be the optimum C source for cacao, and $7 \mathrm{~g} \cdot$ liter $^{-1}$ agar (Sigma), with $\mathrm{pH}$ adjusted to 5.3 before autoclaving. The test tubes were capped with polypropylene closures (Magenta Corp., Chicago, Ill.) which permit gas exchange. The tubes were placed under one of six different $\mathrm{CO}_{2}$ levels in the chambers [average $\mathrm{CO}_{2}$ concentrations $463 \mathrm{ppm}$ (growth room ambient), $2130 \mathrm{ppm}, 5430 \mathrm{ppm}, 9680 \mathrm{ppm}, 19,750$ ppm, and 30,200 ppm] and four photosynthetic photon fluxes (32, 
40, 51, and $106 \mu \mathrm{mol} \cdot \mathrm{m}^{-2} \cdot \mathrm{s}^{-1}$ ) obtained by cheese-cloth shading inside the chamber. Control test tubes (without axillary shoots) were included in all chambers. Carbon dioxide levels were monitored daily in chambers, and test tubes with and without shoots were sampled after 30 days in culture. There were 20 tubes in each $\mathrm{CO}_{2}$-light treatment. Data on total shoot elongation, number of leaves, and budbreak were taken 30 and 60 days after initiating treatment, and total leaf area was obtained after 60 days with a leaf-area meter (model LI-3000; LI-COR, Lincoln, Neb.). The parameters budbreak and total number of leaves were square root transformed.

Statistical analysis was performed using SAS (version 6.07) programs [analysis of variance (ANOVA) and regression]. The layout was a split-plot with no replications. Because no valid test existed for $\mathrm{CO}_{2}$ and light levels, we used the variation among plants in every $\mathrm{CO}_{2}$-light combination for all statistical tests on the assumption that the error (a) and components (b) were 0 .

In a second experiment to determine if light was necessary for the $\mathrm{CO}_{2}$ effect, axillary cotyledonary shoots were placed in chambers with ambient or high $\mathrm{CO}_{2}(20,000 \mathrm{ppm})$, under either high light $\left(120 \mu \mathrm{mol} \cdot \mathrm{m}^{-2} \cdot \mathrm{s}^{-1}\right)$ or in darkness achieved by loosely wrapping tube racks in aluminum foil. Each treatment consisted of 15 tubes. Data for leaf number and shoot elongation were obtained after 30 days.

Net photosynthesis estimation. Net photosynthesis estimation of tissue culture explants, using forced air-mixing systems and an infrared gas analyzer, causes conditions that differ from normal culture atmosphere (e.g., gas diffusion, altered water relations), restricting the validity of results (Kozai, 1991). Alternatively, Kozai and Iwanami (1988) proposed a method to estimate net photosynthesis based on differences in $\mathrm{CO}_{2}$ concentration inside and outside the culture vessel: $\mathrm{P}_{\mathrm{n}}=-\mathrm{E} \cdot \mathrm{V} \cdot \mathrm{K}_{\mathrm{c}} \cdot\left(\mathrm{C}_{\mathrm{in}}-\mathrm{C}_{\text {out }}\right)$, where $\mathrm{V}$ is the headspace volume of culture vessel $(44 \mathrm{ml}) ; \mathrm{K}_{c}$ is the conversion factor of $\mathrm{CO}_{2}$ from volume to mass $\left(1.83 \mathrm{mg} \cdot \mathrm{cm}^{-3}\right.$ at $25 \mathrm{C}$ and $1 \mathrm{~atm}$ ); and $\mathrm{C}_{\mathrm{in}}$ and $\mathrm{C}_{\text {out }}$ are the $\mathrm{CO}_{2}$ concentrations in ppm, inside and outside the vessel, respectively. The $\mathrm{CO}_{2}$ concentrations were sampled daily for 12 days during the light period for tubes under six different chamber $\mathrm{CO}_{2}$ levels (listed above) and at flux density of $106 \mu \mathrm{mol} \cdot \mathrm{m}^{-2} \cdot \mathrm{s}^{-1}$. Tubes were sampled using a $1-\mathrm{ml}$ syringe inserted through a silicone septa built into the lids. A different tube was evaluated each day to avoid a carry-over effect. The factor $\mathrm{E}$ is the number of natural air changes per hour of an empty vessel. E was estimated with carbon dioxide as a trace gas, using the following equation, proposed by Fujiwara et al. (1987): $\mathrm{E}=-\ln$ $\left[\left(\mathrm{K}-\mathrm{K}_{\text {out }}\right) /\left(\mathrm{K}_{0}-\mathrm{K}_{\text {out }}\right)\right] / \mathrm{T}$. $\mathrm{K}$ and $\mathrm{K}_{0}$ are the $\mathrm{CO}_{2}$ concentrations inside the vessel at time $t$ and 0 , respectively; $\mathrm{K}_{\text {out }}^{2}$ is the constant $\mathrm{CO}_{2}$ concentration outside the vessel; and $\mathrm{T}$ is the time interval expressed in hours. This parameter $\mathrm{E}$ was estimated under our conditions to be equal to 1.03 air changes per hour.

Ethylene production under various $\mathrm{CO}_{2}$ levels. In the first experiment, test tubes containing either 1, 2, or 3 axillary shoots cultured on $10 \mathrm{ml}$ of WPM supplemented with $88.8 \mathrm{~mm}$ fructose and $7 \mathrm{~g} \cdot$ liter $^{-1}$ agar, pH 5.3, were capped with air-tight rubber serum caps, and air was sampled for $72 \mathrm{~h}$. There were five tubes per treatment. Ethylene was measured using a gas chromatograph (model 3000; Varian, Walnut Creek, Calif.) with an alumina column and flame-ionization detector. The second experiment was conducted using polycarbonate jars (Magenta GA7; Magenta Corp., Chicago) with a total volume of $375 \mathrm{ml}$, containing $50 \mathrm{ml}$ of the same culture media described previously. Each lid had a silicone septa inserted. The jars were placed in chambers at 450 ppm (ambient), 2000 ppm, and 16,000 ppm $\mathrm{CO}_{2}$ concentration. There were 10 jars per treatment. Ethylene was sampled at 1, 7, and 14 days after explantation.
Nutrient uptake. Axillary shoots were cultured in test tubes capped with plastic closures (Magenta Corp., Chicago) containing $10 \mathrm{ml} \mathrm{WPM}$ supplemented with $88.8 \mathrm{~mm}$ fructose and $7 \mathrm{~g} \cdot \mathrm{liter}^{-1}$ agar, pH 5.3. Initial fresh weight of shoots was determined by weighing each test tube with medium, before and after explantation. Test tubes with and without axillary shoots were placed randomly under three $\mathrm{CO}_{2}$ levels: ambient (423 ppm), $2250 \mathrm{ppm}$, or $30,970 \mathrm{ppm}$, all at PPF of $90 \mu \mathrm{mol} \cdot \mathrm{m}^{-2} \cdot \mathrm{s}^{-1}$. Tubes with medium but without shoots were used as a control. Axillary shoots that were sampled randomly at the beginning of the experiment, weighed, and frozen represent the initial nutrient measurements. Every 10 days for 60 days, five test tubes were sampled for each $\mathrm{CO}_{2}$ treatment. The shoots were removed from the tubes, weighed, and stored frozen. The five control tubes without shoots also were harvested and stored. At the end of the experiment, shoots (leaves plus stems) and the media were dried at $60 \mathrm{C}$ for $24 \mathrm{~h}$ and dry weights were determined. The experiment consisted of 190 tubes (three $\mathrm{CO}_{2}$ treatments $\times$ six collection dates $\times$ five tubes with and five tubes without shoots, plus ten tubes sampled at time 0 . The media depletion experiment was based on three plants from each $\mathrm{CO}_{2}$ chamber at each sampling date.

Dried axillary shoots (stem and leaves) were ground with a mortar and pestle, and a sample of $100 \mathrm{mg}$ dry weight for each $\mathrm{CO}_{2}$ treatment at each 10-day interval was digested using a perchloric acid-hydrogen peroxide method (Adler and Wilcox, 1985). A 100mg sample of dried medium also was digested under the same conditions. Potassium, $\mathrm{Ca}$, and $\mathrm{Mg}$ contents were determined using an atomic absorption spectrophotometer (model Spectra AA 10; Varian Techtron Pty. Ltd., Mulgrave, Victoria, Australia). Phosphorus was determined by the molybdenum blue method (ammonium molybdate-sodium sulfite, 1,2,4-naphthol sulfonic acid procedure) (Jackson, 1948). Fructose was determined enzymatically with a kit supplied by Boehringer-Mannheim Biochemicals (Indianapolis).

\section{Results}

\section{Effect of $\mathrm{CO}_{2}$ concentration and illumination}

The $\mathrm{CO}_{2}$ effect after 60 days was highly significant ( $1 \%$ level) for total shoot elongation, total number of leaves, and leaf area per explant, with the highest values at the highest $\mathrm{CO}_{2}$ level $(30,200$ ppm) (Table 1 and Fig. 1). In contrast, budbreak decreased with increasing $\mathrm{CO}_{2}$ concentrations (significant at $P=0.05$ ). When total $\mathrm{CO}_{2}$ effect variance was partitioned into components, the linear component was highly significant for total elongation and total leaf area (Table 1). The total number of leaves was significant for the linear and quadratic component. The total and partitioned light components were not significant for any of the measured growth parameters. The interaction between $\mathrm{CO}_{2}$ and light was not significant for total shoot elongation or total leaf area. Our analyses using plant-to-plant error assumed error (a) and error (b) variance components equalled 0 . That this assumption was reasonable was evident in that the mean squares for the $\mathrm{CO}_{2}$ quadratic and higher order sources for stem elongation and leaf area were less than the plant-to-plant error as shown in Table 1. In the case of number of leaves and number of budbreaks, the cubic and higher order sources were either less or nonsignificant from plant-to-plant error.

In the second experiment, axillary cotyledonary shoots were placed under high or low $\mathrm{CO}_{2}$ at high light or dark conditions to determine if the $\mathrm{CO}_{2}$ effect could be separated from photosynthesis per se. At high light, $\mathrm{CO}_{2}$ enrichment increased the number of leaves and shoot elongation, but in darkness the number of leaves 
Table 1. Main effect of increasing light and $\mathrm{CO}_{2}$ levels on axillary cotyledonary shoot of cacao elongation, number of leaves, leaf area, budbreak, and root number, 60 days after treatments were imposed.

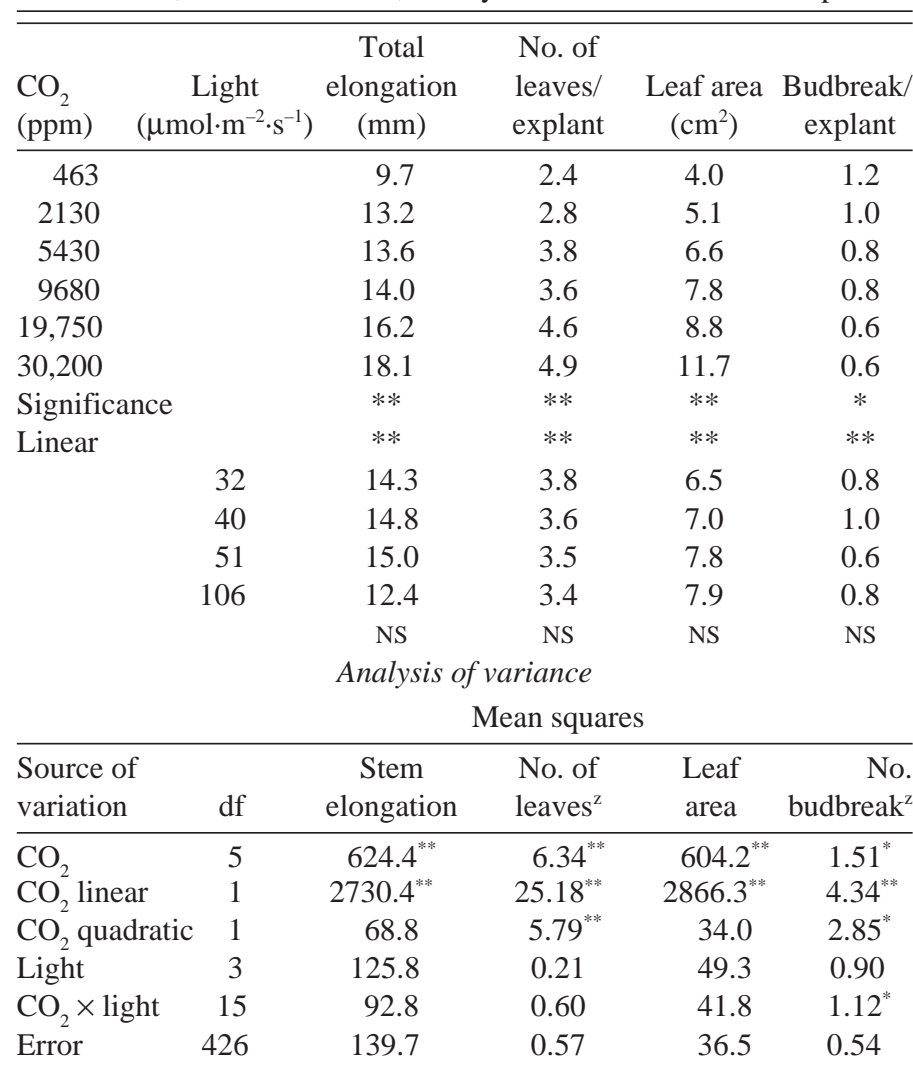

${ }^{*},{ }^{* * *}$ Nonsignificant or significant at $P=0.05$ and 0.01 , respectively. ${ }^{\mathrm{z} S q u a r e}$ root transformed.
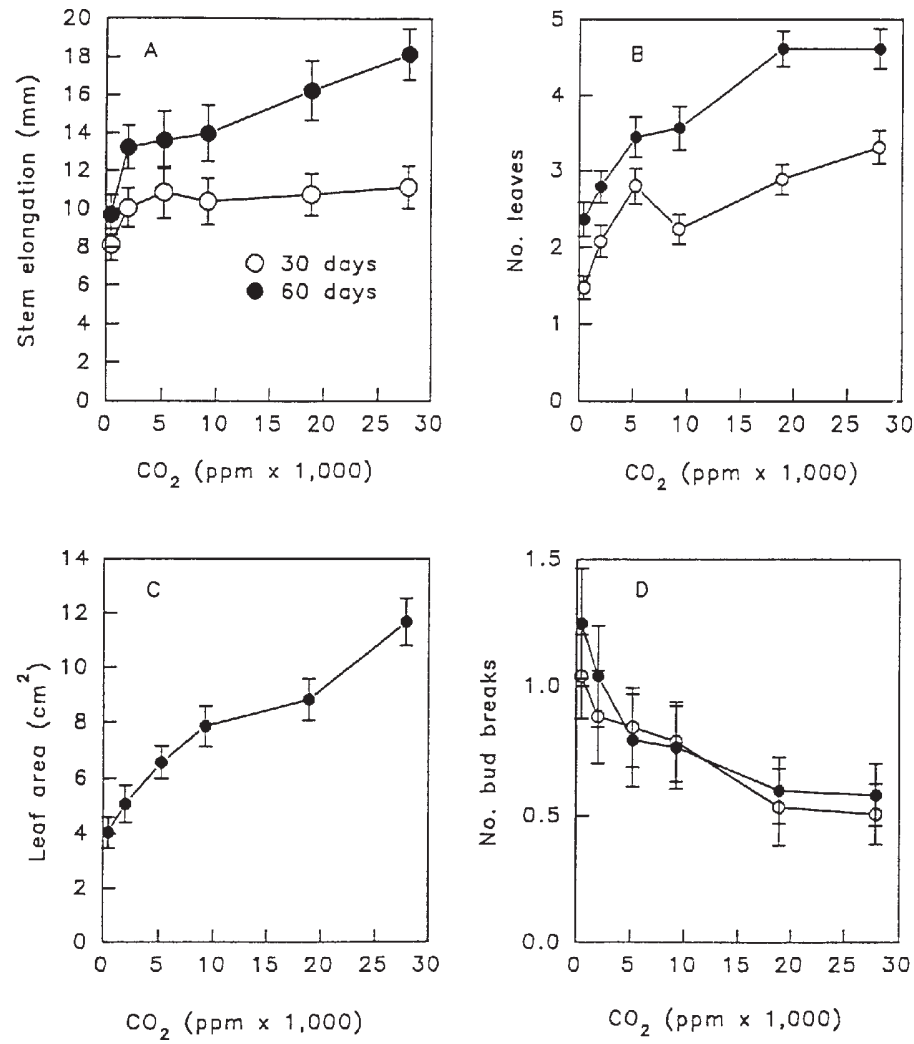

Fig. 1. Response of cacao cotyledonary axillary shoots to $\mathrm{CO}_{2}$ concentrations.
Table 2. Effect of $\mathrm{CO}_{2}$ and light on shoot elongation and leaf development of axillary cotyledonary shoots of cacao.

\begin{tabular}{lcc}
\hline \hline PPF & \multicolumn{2}{c}{$\mathrm{CO}_{2}(\mathrm{ppm})$} \\
\cline { 2 - 3 }$\left(\mu \mathrm{mol} \cdot \mathrm{m}^{-2} \cdot \mathrm{s}^{-1}\right)$ & 500 & 20,000 \\
\hline \multicolumn{3}{c}{ Shoot elongation $(\mathrm{mm} \pm \mathrm{sE})$} \\
0 & $3.9 \pm 2.2$ & $1.8 \pm 0.6$ \\
135 & $1.9 \pm 0.5$ & $6.1 \pm 2.1$ \\
& \multicolumn{2}{c}{ No. of leaves $\pm S E$} \\
0 & $0.6 \pm 0.2$ & $0.5 \pm 0.2$ \\
135 & $1.4 \pm 0.3$ & $2.8 \pm 0.3$ \\
\hline
\end{tabular}

decreased at both $\mathrm{CO}_{2}$ levels, whereas shoot elongation decreased at high $\mathrm{CO}_{2}$ (Table 2). The increase in elongation at low $\mathrm{CO}_{2}$ in darkness appears to be an etiolation effect.

\section{Net photosynthesis estimation}

Estimates of net photosynthesis using the $\mathrm{CO}_{2}$ concentration differential from inside tubes with shoots to chamber concentration showed an increase in net photosynthesis that was proportional to $\mathrm{CO}_{2}$ up to $30,200 \mathrm{ppm}$ (Table 3). This appears to be an overestimation of net photosynthesis because $\mathrm{CO}_{2}$ concentrations inside tubes without shoots were much lower than chamber levels at the two highest $\mathrm{CO}_{2}$ concentrations. Estimation of net photosynthesis using the $\mathrm{CO}_{2}$ differential within tubes with and without shoots indicated a 3.5 -fold increase from 463 to $2639 \mathrm{ppm} \mathrm{CO}$, and a 1.5-fold increase from 2639 to $14,849 \mathrm{ppm} \mathrm{CO}_{2}$ (Table 3). Net photosynthesis estimates declined, however, from 14,849 to $24,015 \mathrm{ppm} \mathrm{CO}_{2}$.

\section{Ethylene production by cacao shoots}

In the first experiment, cacao shoots were cultured in test tubes sealed with air-tight serum closures. The presence of cacao shoots (one to three) in the tube increased the levels of measured ethylene over time (Table 4), as compared to the control (no shoots). Ethylene concentration, however, also increased in tubes without shoots. (This increase in ethylene in tubes with media but without shoots has been found in other experiments.) Ethylene concentrations in tubes with one to three shoots were similar until $4 \mathrm{~h}$ after explantation. From 4 to $22 \mathrm{~h}$, ethylene concentration increased sharply in tubes with two or three shoots. The peak for ethylene detection occurred between 24 and $48 \mathrm{~h}$. Ethylene concentration at $48 \mathrm{~h}$ was directly proportional to the number of shoots present, suggesting that large amounts of ethylene produced by cacao axillary shoots were retained in the tube. It should be noted that conventional culture conditions employ gas-permeable closures.

Ethylene levels were determined in Magenta GA7 vessels (not air-tight) under three $\mathrm{CO}_{2}$ regimes, each containing one shoot. Elevated $\mathrm{CO}_{2}$ concentration increased ethylene concentration (Table 5). The ethylene concentration at $2000 \mathrm{ppm}$ was significantly higher than at ambient, and at $16,000 \mathrm{ppm}$ was significantly higher than at either ambient or $2000 \mathrm{ppm}$. Thus, high $\mathrm{CO}_{2}$ concentration led to an increase of detectable ethylene. Ethylene concentration was maximal at 7 days.

\section{Nutrient uptake}

Shoot growth. Because initial fresh weight significantly affected the growth of the shoots for all treatments (covariate analysis, data not shown), shoot growth data have been expressed as cumulative increases in fresh weight (difference of fresh weight between a given time and the beginning of the experiment) (Fig. 2), 
Table 3. Estimation of net photosynthesis at various $\mathrm{CO}_{2}$ levels, under PPF of $104 \mu \mathrm{mol} \cdot \mathrm{m}^{-2} \cdot \mathrm{s}^{-1}$. The number of air changes per hour was considered constant for all $\mathrm{CO}_{2}$ levels $\left(\mathrm{E}=1.03 \cdot \mathrm{h}^{-1}\right)$.

\begin{tabular}{|c|c|c|c|c|}
\hline \multirow{2}{*}{\multicolumn{3}{|c|}{$\mathrm{CO}_{2}$ concn $(\mathrm{ppm})$}} & \multicolumn{2}{|c|}{ Net photosynthesis $\left(\mu \mathrm{g} \mathrm{CO}_{2} /\right.$ plantlet per $\left.\mathrm{h}\right)$} \\
\hline & & & \multirow{2}{*}{$\begin{array}{c}\text { Difference } \\
\text { between tube with } \\
\text { shoot to chamber } \\
{[(\mathrm{a}-\mathrm{c}) \times \text { constant }]}\end{array}$} & \multirow{2}{*}{$\begin{array}{r}\text { Difference between } \\
\text { tube with shoot to } \\
\text { tube without shoot } \\
{[(\mathrm{b}-\mathrm{c}) \times \text { constant }]}\end{array}$} \\
\hline $\begin{array}{l}\text { Chamber } \\
\text { (ppm) } \\
{[\mathrm{a}]}\end{array}$ & $\begin{array}{c}\text { Tube- } \\
\text { shoot } \\
{[\mathrm{b}]}\end{array}$ & $\begin{array}{c}\text { Tube }+ \\
\text { shoot } \\
{[\mathrm{c}]}\end{array}$ & & \\
\hline $463 \pm 8^{z}$ & $409 \pm 55$ & $235 \pm 51$ & $26.5 \pm 4.3$ & $20.5 \pm 3.9$ \\
\hline $2,130 \pm 85$ & $2639 \pm 356$ & $2,383 \pm 510$ & $72.2 \pm 17.0$ & $73.2 \pm 17.1$ \\
\hline $5,430 \pm 258$ & $5469 \pm 431$ & $5,101 \pm 380$ & $83.5 \pm 30.3$ & $77.6 \pm 26.7$ \\
\hline $9,680 \pm 341$ & $9965 \pm 698$ & $9,439 \pm 632$ & $118.7 \pm 41.0$ & $90.0 \pm 14.8$ \\
\hline $19,750 \pm 524$ & $14,849 \pm 543$ & $13,856 \pm 610$ & $395.8 \pm 43.5$ & $110.9 \pm 27.4$ \\
\hline $30,200 \pm 855$ & $24,015 \pm 716$ & $23,663 \pm 762$ & $474.9 \pm 54.1$ & $76.7 \pm 18.9$ \\
\hline
\end{tabular}

Table 4. Determination of ethylene accumulation from cacao axillary cotyledonary shoots cultures in test tubes capped with air-tight serum cap.

\begin{tabular}{lcccc}
\hline \hline & \multicolumn{4}{c}{ Ethylene concentration (nl-liter ${ }^{-1}$ ) } \\
\cline { 2 - 5 } Time & \multicolumn{4}{c}{ No. shoot } \\
nyyyy$(\mathrm{h})$ & 0 & 1 & 2 & 3 \\
\hline 0.5 & $14.2 \pm 0.6^{\mathrm{z}}$ & $25.4 \pm 2.5$ & $17.8 \pm 1.2$ & $16.6 \pm 0.0$ \\
1.5 & $14.2 \pm 0.4$ & $26.6 \pm 0.9$ & $19.1 \pm 1.2$ & $16.6 \pm 0.0$ \\
4 & $16.6 \pm 0.0$ & $30.8 \pm 3.1$ & $37.6 \pm 4.9$ & $30.6 \pm 0.9$ \\
22 & $22.8 \pm 1.3$ & $43.8 \pm 5.4$ & $140.8 \pm 44.1$ & $100.0 \pm 29.6$ \\
24 & $22.8 \pm 0.4$ & $45.5 \pm 4.6$ & $146.3 \pm 45.2$ & $109.2 \pm 29.6$ \\
48 & $31.5 \pm 1.9$ & $63.0 \pm 12.3$ & $120.4 \pm 14.8$ & $153.7 \pm 50.0$ \\
72 & $21.6 \pm 1.6$ & $48.6 \pm 10.4$ & $96.9 \pm 27.7$ & $86.1 \pm 36.1$ \\
\hline $\mathrm{z} \pm$ SE. & & &
\end{tabular}

Table 5. Ethylene concentration detected on cacao axillary shoots cultures in polycarbonate Magenta GA7 vessels, closed with polypropylene lids, at various times after explantation.

\begin{tabular}{lcccr}
\hline \hline $\begin{array}{l}\text { Time } \\
\text { (days) }\end{array}$ & \multicolumn{4}{c}{ Ethylene $\left(\mathrm{nl} \cdot\right.$ liter $\left.^{-1}\right)$} \\
\cline { 2 - 5 } & $450 \mathrm{ppm} \mathrm{CO}_{2}$ & $2,000 \mathrm{ppm} \mathrm{CO}_{2}$ & $16,000 \mathrm{ppm} \mathrm{CO}_{2}$ & $\mathrm{Avg}$ \\
\hline 1 & $3.2 \pm 0.4^{\mathrm{z}}$ & $3.2 \pm 0.4$ & $7.3 \pm 2.0$ & 4.6 \\
7 & $6.8 \pm 0.4$ & $17.1 \pm 2.3$ & $22.9 \pm 1.1$ & 15.6 \\
14 & $7.3 \pm 2.0$ & $7.4 \pm 1.1$ & $12.6 \pm 1.3$ & 9.2 \\
Avg & $5.8 \mathrm{a}^{\mathrm{y}}$ & $9.1 \mathrm{~b}$ & $14.1 \mathrm{c}$ & \\
\hline
\end{tabular}

${ }^{\mathrm{z}} \pm$ SE.

${ }^{y}$ Mean separation by Duncan's multiple range test at $P=0.05$.

and as fresh weight gain per day (Fig. 3). Although dry weight increases followed fresh weight fairly closely, only fresh weight data are discussed since initial dry weight of shoots in treatment could not be assessed. Final fresh weight of shoots was significantly improved by increasing $\mathrm{CO}_{2}$ (Fig. 2). Cumulative increase in fresh weight initially was minor, but after 30 days the differences between ambient and $\mathrm{CO}_{2}$ enrichment treatments enlarged, but only with small differences between the two elevated $\mathrm{CO}_{2}$ regimes (Fig. 2). Shoots kept at ambient $\mathrm{CO}_{2}$ had little increase in fresh weight for 50 days (while dry weight actually decreased during this period).

Increasing $\mathrm{CO}_{2}$ concentration significantly increased the growth rate as determined by the fresh weight, with the highest rate occurring at the highest $\mathrm{CO}_{2}$ level (Fig. 3). The fresh weight growth rate generally was constant over time. The improved growth under increased $\mathrm{CO}_{2}$ concentration was a result of cumulative increase over time. Although the average increase in fresh weight from

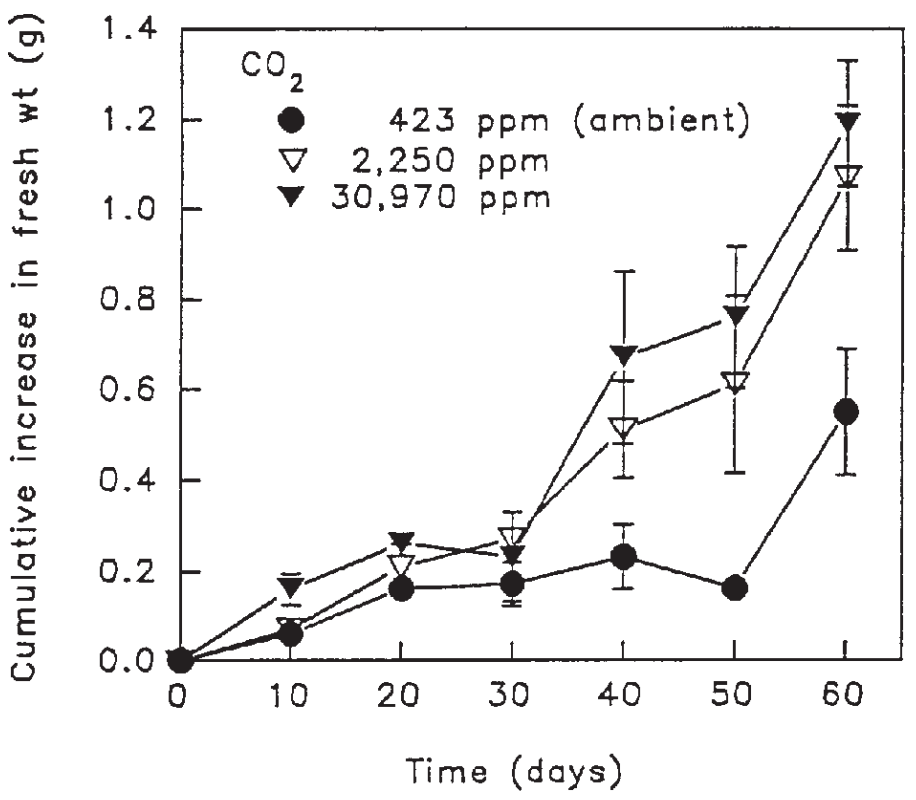

Fig. 2. Fresh weight accumulation by axillary cotyledonary shoots of cacao grown under three $\mathrm{CO}_{2}$ regimes.

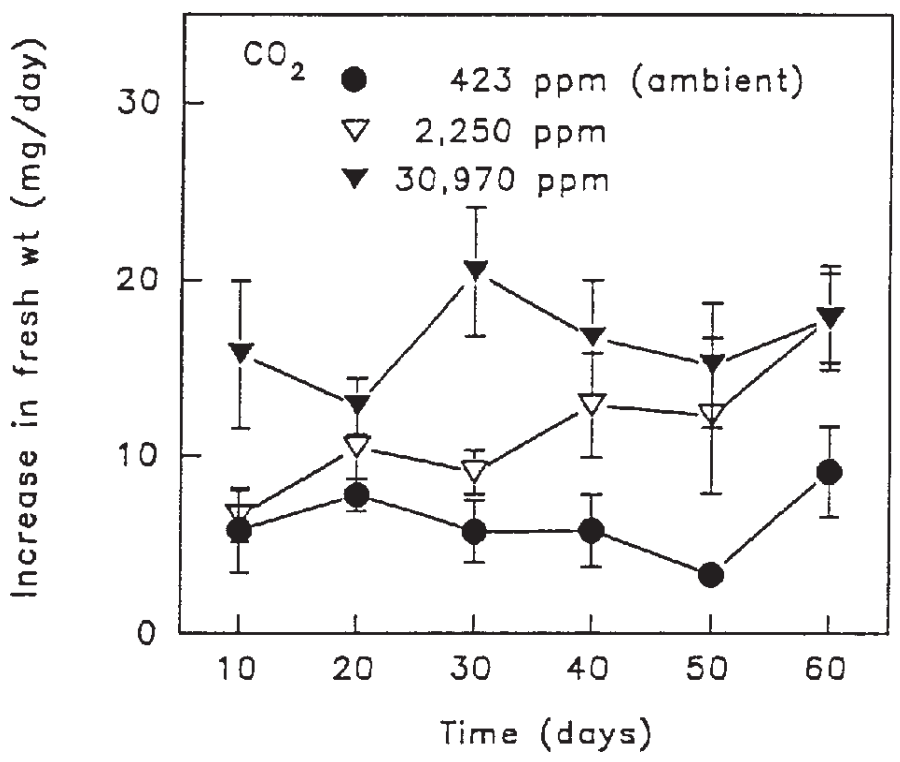

Fig. 3. Daily fresh weight increase in cotyledonary axillary shoots of cacao grown under three $\mathrm{CO}_{2}$ regimes. 


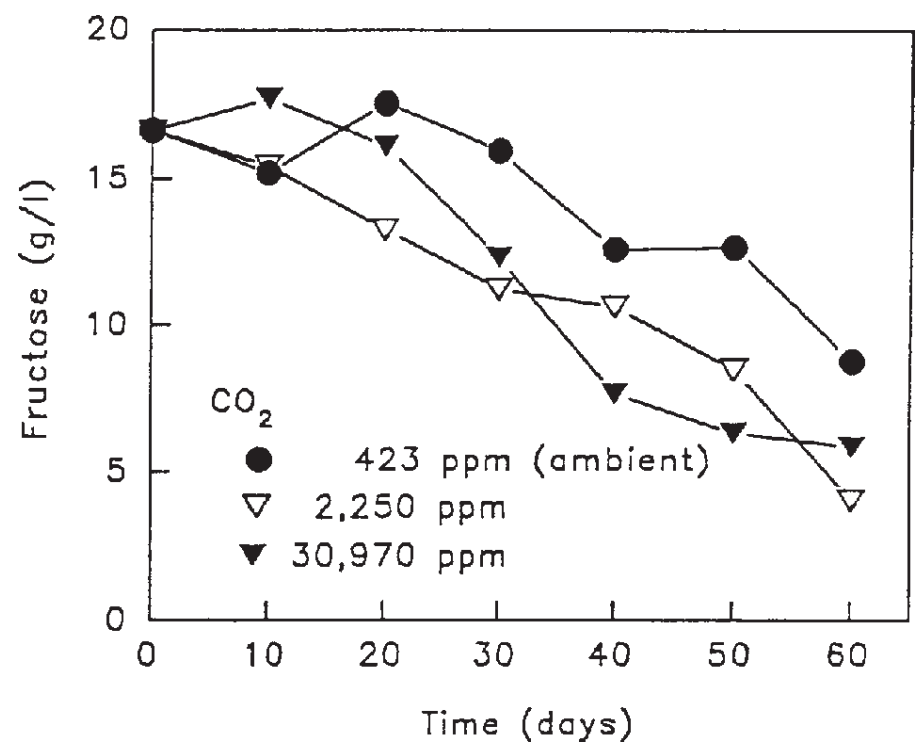

Fig. 4. Fructose depletion from media with cotyledonary axillary shoots of cacao grown under three $\mathrm{CO}_{2}$ regimes.

shoots cultured under $\mathrm{CO}_{2}$ concentrations of 2250 and 30,970 ppm did not differ significantly, the fresh weights at the very high $\mathrm{CO}_{2}$ levels always were highest.

Fructose. Fructose was depleted from the medium in all $\mathrm{CO}_{2}$ treatments, but at different rates (Fig. 4). Under both elevated $\mathrm{CO}_{2}$ conditions (2250 and 30,970 ppm), fructose was consumed at similar rates, with about $40 \%$ of the initial concentration used during the first 30 days, and about $70 \%$ for the whole 60-day period. However, at ambient $\mathrm{CO}_{2}$ only $5 \%$ of the original concentration was consumed during the first 30 days, and about $50 \%$ in the following 30-day period. The consumption of fructose paralleled the net cumulative growth response.

Elements. The initial fresh weight of explants did not affect the rate of nutrient uptake for any of the elements analyzed (covariate analysis, data not shown). The three $\mathrm{CO}_{2}$ levels tested caused no striking differences in the nutrient concentration of shoots (leaves plus stems), and these results were consistent with the values reported for field-grown plants by Murray (1967) (Fig. 5).

Significance of the $\mathrm{CO}_{2}$ effect based on analysis of variance (ANOVA) is shown in Table 6. In the nutrient depletion experiment $\mathrm{K}$ and $\mathrm{Ca}$ showed a significant $\mathrm{CO}_{2} \times$ date interaction, so interaction mean square was used to compute significance for main effects, as this was the more conservative test. Potassium depletion of the medium was proportional to shoot growth, i.e., depletion was greatest under enriched $\mathrm{CO}_{2}$ (Fig. 5A). Nutrient depletion from the medium under ambient $\mathrm{CO}_{2}$ was significantly lower than under enriched $\mathrm{CO}_{2}$, but there was no apparent difference in nutrient depletion between both enriched $\mathrm{CO}_{2}$ treatments after 20 days. At the end of the 60 -day period, about $50 \%$ of the initial $\mathrm{K}$ remained in the medium under ambient conditions, as compared to $20 \%$ and 24\%, respectively, under 2250 and 30,970 ppm $\mathrm{CO}_{2}$. Potassium concentration of shoots under ambient $\mathrm{CO}_{2}$ increased over time (Fig. 5B). Potassium tissue concentration from 30 to 60 days was highest under ambient $\mathrm{CO}_{2}$.

The rate of $\mathrm{Ca}$ depletion from the medium was less than that of $\mathrm{K}$ depletion and was not associated with shoot growth (Fig. 5C). After 60 days, the remaining $\mathrm{Ca}$ level was about $77 \%$ for ambient and about $70 \%$ for enriched $\mathrm{CO}_{2}$ conditions. The $\mathrm{CO}_{2}$ effect was not significant, but under the ambient $\mathrm{CO}_{2}$ regime $\mathrm{Ca}$ in the medium usually remained at higher concentration than under
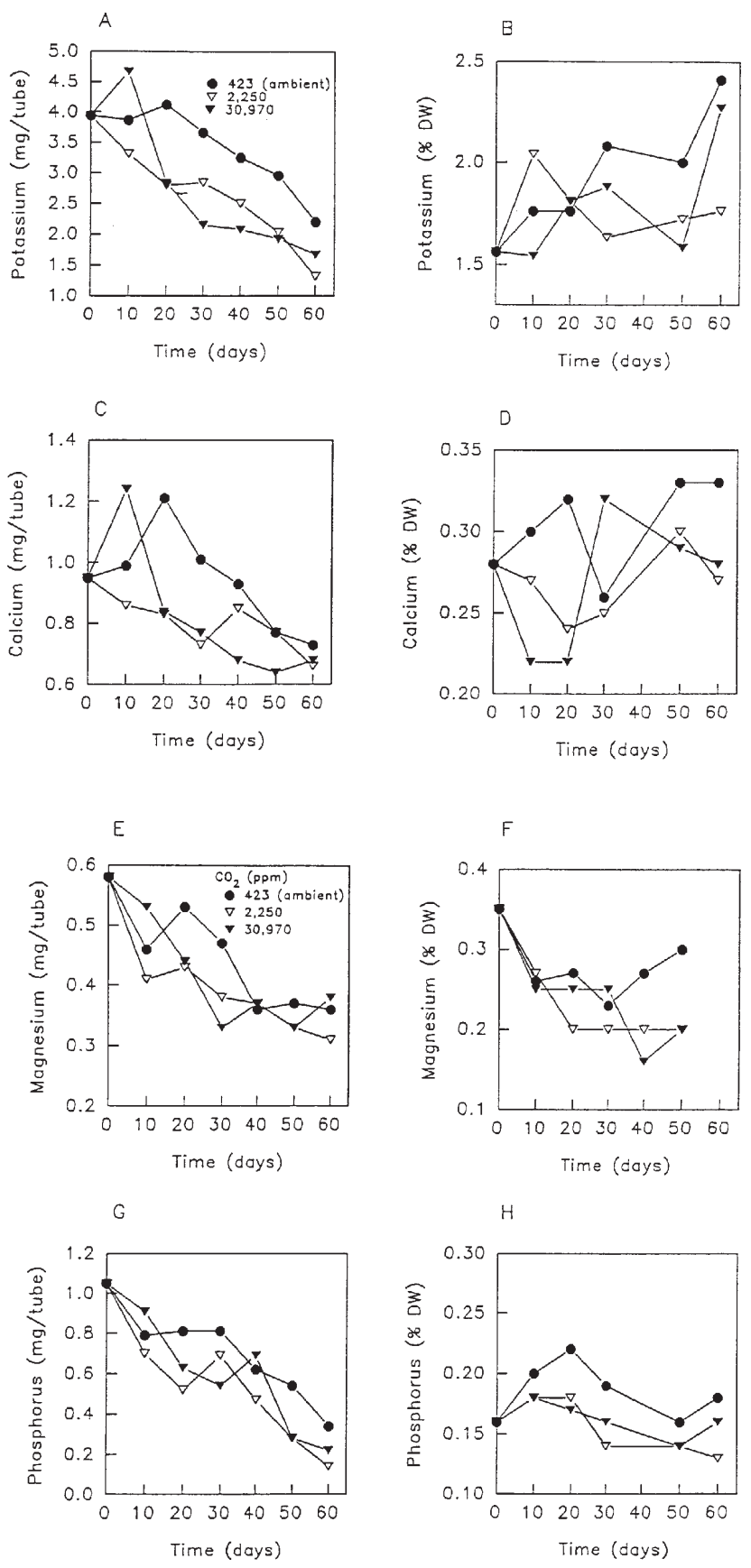

Fig. 5. Media depletion (left) and tissue concentration (right) of cotyledonary axillary shoots of cacao grown under three $\mathrm{CO}_{2}$ regimes $(423,2250$, or 30,970 ppm): potassium (A and $\mathbf{B})$; calcium (C and $\mathbf{D})$; magnesium ( $\mathbf{E}$ and $\mathbf{F})$; and phosphorus ( $\mathbf{G}$ and $\mathbf{H})$.

Table 6. Significance of $\mathrm{CO}_{2}$ and time effect on nutrient depletion by in vitro-grown axillary shoots.

\begin{tabular}{lccccc}
\hline \hline Source of variation & $\mathrm{DF}$ & $\mathrm{K}$ & $\mathrm{Ca}$ & $\mathrm{Mg}$ & $\mathrm{P}$ \\
\hline $\mathrm{CO}_{2}$ & 2 & $*$ & $\mathrm{NS}$ & $\mathrm{NS}$ & $*$ \\
Linear & 1 & $\mathrm{NS}$ & $\mathrm{NS}$ & $\mathrm{NS}$ & $\mathrm{NS}$ \\
Quadratic & 1 & $* *$ & $\mathrm{NS}$ & $*$ & $*$ \\
Time & 6 & $* *$ & $\mathrm{NS}$ & $* *$ & $* *$ \\
Linear & 1 & $* *$ & $* *$ & $* *$ & $* *$ \\
Quadratic & 1 & $\mathrm{NS}$ & $\mathrm{NS}$ & $*$ & $\mathrm{NS}$ \\
$\mathrm{CO}_{2} \times$ time & 12 & $*$ & $* *$ & $\mathrm{NS}$ & NS
\end{tabular}

$\mathrm{Ns}^{, *},{ }^{* *}$ Nonsignificant or significant at $P=0.05$ or 0.01 , respectively. 
enriched $\mathrm{CO}_{2}$ (Fig. 5C). There was no strong evidence that $\mathrm{Ca}$ concentration in shoots varied due to $\mathrm{CO}_{2}$ treatment, but concentration was generally higher under ambient $\mathrm{CO}_{2}$ (Fig. 5D).

Magnesium was depleted from the medium at about the same rate for all $\mathrm{CO}_{2}$ treatments, implying that the rate of $\mathrm{Mg}$ uptake was unaffected by growth (Fig. 5E). After 60 days, Mg levels in medium ranged from about $62 \%$ for ambient $\mathrm{CO}_{2}, 53 \%$ at 2250 ppm $\mathrm{CO}_{2}$, and $65 \%$ at 30,970 ppm $\mathrm{CO}_{2}$. Under enriched $\mathrm{CO}_{2}$ treatments, $\mathrm{Mg}$ concentration of shoots tended to decline over time (Fig. 5F), but under ambient $\mathrm{CO}_{2}$ concentrations remained constant after an initial drop.

The rate of $\mathrm{P}$ depletion from the medium was significantly affected by $\mathrm{CO}_{2}$ and was proportional to shoot growth (Fig 5G). At the end of 60 days, $\mathrm{P}$ was essentially depleted from all $\mathrm{CO}_{2}$ treatments, but depletion was least under ambient $\mathrm{CO}_{2}$. About $13 \%$ of the original $\mathrm{P}$ remained at $2250 \mathrm{ppm} \mathrm{CO}$, as compared to $21 \%$ at 30,970 , and $32 \%$ at ambient $\left(423 \mathrm{ppm} \mathrm{CO}_{2}\right)$. Tissue $\mathrm{P}$ levels were highest in ambient $\mathrm{CO}_{2}$ (Fig. $5 \mathrm{H}$ ).

\section{Discussion}

The results of these experiments confirm the recalcitrance of cacao under conventional protocols and the promotive effects of $\mathrm{CO}_{2}$ enrichment reported by Figueira et al. (1991). Shoot growth and development improved as $\mathrm{CO}_{2}$ concentration in the chambers increased from ambient to $30,200 \mathrm{ppm}$ (tube concentration = $24,015 \mathrm{ppm}$ ) but the effect was not directly proportional, as concentration was greatest at the lower levels of increase (Fig. 1). The most direct developmental response to increased $\mathrm{CO}_{2}$ was increased leaf area (Fig. 1C) attributable both to increased number of leaves and increased leaf surface. Another nonphotosynthetic effect of increasing $\mathrm{CO}_{2}$ was decreased budbreak.

The simplest explanation for the $\mathrm{CO}_{2}$ effect on in vitro performance is increased photosynthesis and, indeed, light was necessary for the $\mathrm{CO}_{2}$ effect (Table 2). The increase in dry weight of plants grown under enriched $\mathrm{CO}_{2}$ concentration (Fig. 3) is typically a result of increased C fixation (Mott, 1990). However, the effect of light levels was not significant (Table 1), suggesting that although photosynthesis plays a key role in improving cacao shoot growth and development, an additional effect is involved. Estimation of net photosynthesis based on $\mathrm{CO}_{2}$ depletion within tubes indicated an increase up to $14,849 \mathrm{ppm}$ but a decline at 23,663 (Table 3), despite a corresponding increase in growth and development.

The full explanation for the response of cacao in vitro to such high levels of $\mathrm{CO}_{2}$ remains baffling. Guers (1985) reported that net photosynthesis of cacao cuttings in the field was nearly saturated at $600 \mathrm{ppm} \mathrm{CO}_{2}$. Increased net photosynthesis may derive either from improved $\mathrm{CO}_{2}$ uptake, inhibition of photorespiration, or both. Carbon dioxide uptake may be lower under in vitro conditions due to the absence of turbulence, which contributes to a large boundary layer resistance. Carbon dioxide effects on stomatal regulation are unlikely to be involved because of the high humidity in vitro environment. An unexplored explanation was alteration of intracellular pH (Bown 1985).

We considered the possibility of a $\mathrm{CO}_{2}$ effect on ethylene that could suppress growth, but, in fact, ethylene concentration increased with increasing $\mathrm{CO}_{2}$ concentration (Table 4 and 5). It is possible that $\mathrm{CO}_{2}$ could be reducing ethylene response while stimulating its production (Sisler and Wood, 1988).

Elevated $\mathrm{CO}_{2}$ could conceivably influence nutrient absorption. Cacao shoots contain large amounts of polysaccharides (Brooks and Guard, 1952), which have been associated with recalcitrance in vitro (Blake and Maxwell, 1984; Legend et al., 1986; Orchard et al., 1979; and Passey and Jones, 1983). Gum exudation from the cut surfaces of shoots might interfere with in vitro nutrient uptake and/or availability (Figueira et al., 1989). Cacao gum is acidic, rich in uronic acids, and negatively charged under $\mathrm{pH}$ of 5.3. Large amounts of bound $\mathrm{Ca}$ were detected in gum isolated from liquid culture of cacao shoots (Figueira et al., 1991b). Shoots under conventional in vitro culture perform better if roots are present (Figueira et al., 1991).

Fructose uptake, measured by medium depletion, was lowest under ambient $\mathrm{CO}_{2}$ levels (Fig. 4). Similarly, under ambient $\mathrm{CO}_{2}$, nutrient uptake as measured by medium depletion tended to be lowest, while nutrient content of tissues generally was highest, indicating that nutrients were being absorbed but were underutilized under low $\mathrm{CO}_{2}$. The nutrient data, however, produced no clear evidence that elevated $\mathrm{CO}_{2}$ overcomes any interference by gum on nutrient uptake. The low absorption of $\mathrm{Ca}$ and $\mathrm{Mg}$ was not improved by $\mathrm{CO}_{2}$ enrichments despite improved growth. Thus, it is unclear if the increased nutrient uptake found under enriched $\mathrm{CO}_{2}$ atmospheres was the result or the cause of increased growth. The fact that nutrient uptake occurs without significant growth at ambient $\mathrm{CO}_{2}$ levels suggests that the stimulatory effect of $\mathrm{CO}_{2}$ is not a direct effect of $\mathrm{CO}_{2}$ to increase uptake, but rather a direct effect on growth itself.

We conclude that in vitro growth and development of cacao is promoted by increasing levels of $\mathrm{CO}_{2}$ up to tube concentrations of 24,015 ppm. Part, but not all, of the response to high $\mathrm{CO}_{2}$ appears to be explained by an increase in net photosynthesis. The assumption that stem gums are the cause of recalcitrance could not be confirmed or disproved on the basis of nutrient uptake under different $\mathrm{CO}_{2}$ concentrations. Finally, we suggest that $\mathrm{CO}_{2}$ enrichment with tube levels as high or higher than 20,000 ppm might be beneficial for in vitro culture of other recalcitrant tropical species.

\section{Literature Cited}

Adler, P.R. and G.E. Wilcox. 1985. Rapid perchloric acid digest methods for analysis of major elements in plant tissue. Commun. Soil Sci. Plant Anal. 16:1153-1163.

Blake, J. and P. Maxwell. 1984. Tissue culture propagation of cacao by the use of axillary buds. Proc. Intl. Conf. Cocoa and Coconuts, Kuala Lumpur, Malaysia.

Bown, A. 1985. $\mathrm{CO}_{2}$ and intracellular pH. Plant Cell Environ. 8:459-465. Brooks, E.R. and A.T. Guard. 1952. Vegetative anatomy of Theobroma cacao. Bot. Gaz. 13:444-454.

Desjardins, Y., F. Laforge, C. Lussier, and A. Gosselin. 1988. Effect of $\mathrm{CO}_{2}$ enrichment and high photosynthetic photon flux on the development of autotrophy and growth of tissue-cultured strawberry, raspberry, and asparagus plants. Acta Hort. 230:45-53.

Figueira, A., A. Whipkey, and J. Janick. 1989. Gum in Theobroma cacao L.: A potential deterrent for micropropagation, p. 121. Program and Abstracts of the 86th Annu. Meeting of the Amer. Soc. Hort. Sci. 469. (Abstr.)

Figueira, A., A. Whipkey, and J. Janick. 1991. Increased $\mathrm{CO}_{2}$ and light promote in vitro shoot growth and development of Theobroma cacao. J. Amer. Soc. Hort. Sci. 116:585-589.

Figueira, A., A. Whipkey, and J. Janick. 1991a. Elevated $\mathrm{CO}_{2}$ facilitates micropropagation of Theobroma cacao L. 1991 Intl. Cocoa Conf., Kuala Lumpur, Malaysia, 25-28 Sept. 1991. (Abstr.)

Figueira, A., J. Janick, M. Yadav, and J. BeMiller. 1991b. Cacao gum: A potential new economic product. 1991 Intl. Cocoa Conf., Kuala Lumpur, Malaysia, 25-28 Sept. 1991. (Abstr.)

Fujiwara, K., T. Kozai, and I. Watanabe. 1987. Fundamental studies on environments in plant tissue culture vessels. III. Measurements of carbon dioxide gas concentration in closed vessels containing tissue cultured plantlets and estimates of net photosynthetic rates of the 
plantlets. J. Agr. Meteorology 43(1):21-30.

Grout, B.W.W. 1988. Photosynthesis of regenerated plantlets in vitro, and the stresses of transplanting. Acta Hort. 230:129-135.

Grout, B.W.W. and S. Millan. 1985. Photosynthetic development of micropropagated strawberry plantlets following transplanting. Ann. Bot. 55:129-131.

Guers, J. 1985. Potentialites photosynthetiques du cacaoyer (Theobroma cacao L.) en fonction de l'eclairement, de la temperature et du $\mathrm{CO}_{2}$ ambiant. Café, Cacao, Thé 34:245-254.

Infante, R., E. Magnanini, and B. Righetti. 1989. The role of light and $\mathrm{CO}_{2}$ in optimizing the conditions for shoot proliferation of Actinidia deliciosa in vitro. Physiol. Plant. 77:191-195.

Jackson, M.L. 1948. Soil chemistry analysis. Prentice Hall, Englewood Cliffs, N.J.

Janick, J. and A. Whipkey. 1985. Axillary proliferation of shoots from cotyledonary nodal tissue of cacao. Rev. Theobroma 15:125-131.

Kozai, Y. and Y. Iwanami. 1988. Effects of $\mathrm{CO}_{2}$ enrichment and sucrose concentration under high photon fluxes on plantlet growth of carnation (Dianthus caryophyllus L.) in tissue culture during the preparation stage. J. Jpn. Soc. Hort. Sci. 57:279-288.

Kozai, Y. 1991. Autotrophic micropropagation, p. 127-141. In: Y.P.S. Bajaj (ed.). Biotechnology in agriculture and forestry. vol. 17. High-tech and micropropagation. Springer-Verlag, Berlin.

Laforge, F., C. Lussier, Y. Desjardins, and A. Gosselin. 1991. Effect of light intensity and $\mathrm{CO}_{2}$ enrichment during in vitro rooting on subsequent growth of plantlets of strawberry, raspberry, and asparagus in acclimatization. Scientia Hort. 47:259-269.

Lakso, A.N., B.I. Reisch, J. Mortensen, and M.H. Roberts. 1986. Carbon dioxide enrichment for stimulation of growth of in vitro-propagated grapevines after transfer from culture. J. Amer. Soc. Hort. Sci. 111:634638.

Legrand, B. and E. Mississo. 1986. Influence de la taille des explantats et des regulateurs de croissance sur le developpement des tissus de Theobroma cacao L., var. Amelonado cultives in vitro. Café, Cacao, Thé 30:239-246.

Lloyd, G. and B. McCown. 1980. Commercially feasible micropropagation of mountain laurel, Kalmia latiflora, by use of shoot-tip culture. Proc. Intl. Plant Prop. Soc. 30:421-427.

Mott, K.A. 1990. Sensing of atmospheric $\mathrm{CO}_{2}$ by plants. Plant Cell, Environ. 13:731-737.

Murray, D.B. 1967. Leaf analysis applied to cocoa. Cocoa Growers' Bul. 9:25-31. Cadbury Schweppes, Birmingham, UK.

Orchard, J.E., H.A. Collin, and K. Hardwick. 1979. Culture of shoot apices of Theobroma cacao. Physiol. Plant. 47:207-210.

Passey, A.J. and O.P. Jones. 1983. Shoot proliferation and rooting in vitro of Theobroma cacao L. type amelonado. J. Hort. Sci. 58:589-592.

Sisler, E.C. and C. Wood. 1988. Interaction of ethylene and $\mathrm{CO}_{2}$. Physiol. Plant. 73:440-444.

Woltering, E.J. 1990. Beneficial effects of carbon dioxide on development of gerbera and rose plantlets grown in vitro. Scientia Hort. 44:341-45. 